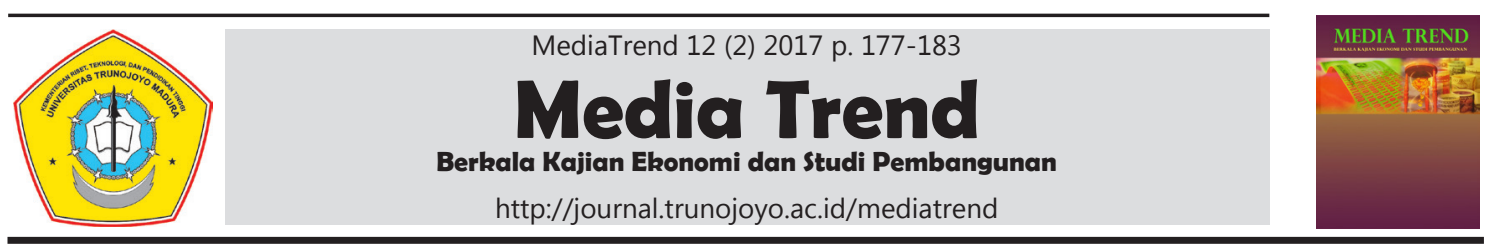

\title{
Industri Rumah Tangga Pangan Olahan Berbahan Baku Ikan Air Tawar Pada Kelompok Wanita Tani di Desa Senden, Kecamatan Mungkid, Ka- bupaten Magelang
}

\author{
Ernoiz Antriyandarti ${ }^{1, *}$, Susi Wuri Ani ${ }^{2}$, \\ ${ }^{1,2}$ Program Studi Agribisnis, Fakultas Pertanian, Universitas Sebelas Maret
}

\section{Informasi Artikel \\ Sejarah artikel: \\ Diterima Maret 2017 \\ Disetujui Agustus 2017 \\ Dipublikasikan Oktober 2017}

\section{Keywords:}

Home Industry,

Processed,

Freshwater Fish,

Farm Women Group

(KWT)

\begin{abstract}
A B S T R ACT
He majority of the residents of Senden Village, Mungkid Subdistrict, Magelang Regency are farmers with the main commodities of paddy whose income from rice farming is very small due to the narrowness of cultivated land $(0.3278 \mathrm{ha})$. To increase household income, residents maintain freshwater fish in the yard of the house or on farms that pass through irrigation channels. This freshwater fish breed has also not yielded encouraging results due to technical marketing constraints. The contribution of freshwater fish cultivation to farm household income is still small, so a member of Senden Women Farmer Group tries to increase the added value of freshwater fish production by processing it into fish chips. This home-based business is not yet developed and economically feasible yet. Therefore, action research activities are conducted to facilitate the mothers of KWT members to pioneer various processed food business with the abundant raw materials available in the village. This research aims to create productive economic activity of Senden Women Farmer Group in order to increase household income by: (1) giving fish fish cracker, fish nugget and fish meatball training professionally, having commercial value and selling merchandise; (2) facilitating the packaging of processed fish products; (3) to provide technical training and storage management of processed fish products to be durable and maintained its quality.
\end{abstract}




\section{Pendahuluan \\ Latar Belakang}

Mayoritas penduduk Desa Senden, Kecamatan Mungkid, Kabupaten Magelang adalah petani dengan komoditas utama padi. Menurut Antriyandarti dan Fukui (2010), pendapatan rumah tangga petani dipengaruhi oleh harga beras, pendidikan, pendapatan off-farm (non-pertanian) dan aset yang dimiliki oleh rumah tangga petani. Pendapatan dari usaha tani padi mempunyai kontribusi sangat kecil dalam pendapatan rumah tangga karena sempitnya lahan yang digarap (0.3278 ha), sehingga kurang mencukupi untuk kebutuhan sehari-hari secara layak. Beberapa kepala keluarga (hanya sekitar $12 \%$ saja) mempunyai pekerjaan sampingan nonpertanian (off-farm jobs) untuk menambah pendapatan keluarga (Antriyandarti, 2016).

Kondisi saluran irigasi yang masih semi-teknis merupakan salah satu faktor penyebab produktivitas padi di desa Senden tidak optimal dan tidak efisien serta berdaya saing (Antriyandarti, 2015). Petani hanya bisa menanam padi 2 kali dalam setahun atau 5 kali dalam dua tahun. Untuk menambah pendapatan rumah tangga, penduduk memelihara ikan air tawar di pekarangan rumah atau di lahan pertanian yang dilewati saluran irigasi.

Budidaya ikan air tawar ini juga belum memberikan hasil yang menggembirakan karena kendala teknis pemasaran. Kontribusi budidaya ikan air tawar terhadap pendapatan rumah tangga tani masih kecil. Kondisi ini mendorong seorang anggota kelompok wanita tani Desa Senden mencoba meningkatkan nilai tambah produksi ikan air tawar dengan mengolahnya menjadi keripik ikan. Dengan pertimbangan ada nilai tambah dan produk yang ditawarkan ke pasar lebih tahan lama dibandingkan menjual dalam bentuk ikan segar. Usaha rumahan ini belum berkembang dan belum mempunyai kelayakan ekonomis. Oleh karena itu, diajukan usulan kegiatan IbM Industri Rumah
Tangga Pangan Olahan Berbahan Baku Ikan Air Tawar pada Kelompok Wanita Tani Di Desa Senden, Kecamatan Mungkid, Kabupaten Magelang guna memfasilitasi ibu-ibu anggota KWT untuk merintis usaha aneka pangan olahan dengan bahan baku yang tersedia melimpah di desa tersebut. Dengan demikian usaha rumahan ini dapat menjadi sumber off-farm income rumah tangga petani di desa Senden. Sebagaimana yang telah dikemukakan oleh Godoy dan Dewbre (2010), De Janvry et al. (2005), serta Babatunde dan Qaim (2009) bahwa off-farm jobs berperan penting dalam mengurangi kemiskinan di pedesaan karena petani berskala kecil dapat meningkatkan pendapatan rumah tangga.

Lokasi Desa Senden yang berdekatan dengan area wisata Candi Borobudur merupakan kelebihan secara geografis dimana lokasi wisata tersebut dapat menjadi target pemasaran produk olahan ikan yang diproduksi Kelompok Wanita Tani Desa Senden, Mungkid, Magelang. Wisatawan domestik dan mancanegara bisa menjadi salah satu segmen pemasaran produk. Pergeseran budaya konsumsi masyarakat yang mulai menyukai makanan praktis cepat saji menjadi peluang pasar tersendiri untuk produk nuget dan bakso ikan air tawar.

\section{Metode Penelitian}

Kegiatan penelitian ini merupakan action research yang dilaksanakan di Desa Senden, Kecamatan Mungkid, Kabupaten Magelang. Kegiatan ini melibatkan anggota Kelompok Wanita Tani untuk berpartisipasi aktif dalam program IbM dengan menggunakan metode Participatory Rural Appraisal (PRA). PRA adalah suatu metode yang menempatkan masyarakat sebagai subyek, perencana, pelaksana, sekaligus sebagai penilai dalam program pemberdayaan sehingga tim pengabdian dan stakeholder yang terlibat sebagai fasilitator dan masyarakat sebagai pelakunya. Kegiatan dilaksanakan setelah pencarian 
informasi mengenai masalah, kebutuhan dan potensi yang ada di desa. Partisipasi berarti masyarakat (dalam hal ini anggota KWT) terlibat dalam proses pendekatan "bottom-up" yang menuntut kemampuan berkomunikasi yang baik dan teknologi yang ditransfer dapat digunakan dalam situasi apapun. (Cavestro, 2003). Partisipasi dalam keiatan ini merujuk pada 3 (tiga) definisi, pertama : partisipasi didefinisikan sebagai gerakan masyarakat untuk terlibat dalam proses pembuatan keputusan, dalam pelaksanaan kegiatan, ikut menikmati hasil kegiatan, dan ikut serta mengevaluasinya (Uphoff, 1988), kedua: partisipasi dianggap sebagai proses dimana berbagai pelaku dapat mempengaruhi serta membagi wewenang dalam menentukan inisiatif-inisiatif pembangunan, serta keputusan serta pengalokasian berbagai sumber daya yang berpengaruh terhadap kehidupan mereka (World Bank, 2004).

Kegiatan ini dilakukan di Kelompok Wanita Tani Desa Senden dengan cara: (1) memberikan pelatihan pengolahan ikan air tawar menjadi kerupuk ikan, nugget ikan, bakso ikan; (2) memfasilitasi pengemasan produk; (3) memberikan pelatihan manajemen penyimpanan (storage management).

\section{Hasil dan Pembahasan \\ Pelatihan Pengolahan Ikan Air Tawar Menjadi Kerupuk Ikan}

Jenis ikan air tawar yang diolah menjadi kerupuk adalah ikan nila. Ikan nila memiliki rasa daging yang gurih dan enak. Proses pembuatan kerupuk ikan disajikan pada Gambar 1.

\section{Pelatihan Pengolahan Ikan Air Tawar Menjadi Nugget Ikan}

Nugget adalah makanan olahan yang terbuat dari bahan dasar tepung, daging ikan tenggiri dan juga bahan pelengkap lainnya.Nugget sangat digemari masyarakat karena sangat praktis untuk dikonsumsi sehari-hari, sehingga produk nugget sangat prospektif di pasar. Ikan nila dan ikan bawal dapat digunakan sebagai bahan baku pembutan nugget ikan. Berikut ini adalah proses pembuatannya (Gambar 2).

\section{Pelatihan Pengolahan Ikan Air Tawar Menjadi Bakso Ikan}

Bakso ikan menjadi salah satu variasi bakso yang cukup diminati masyarakat.Bakso ikan memiliki gizi yang tinggi dan rasa yang gurih, tidak kalah lezatnya dibandingkan bakso daging. Bakso ikan sering menjadi campuran masakan sop, atau bias juga disajikan dengan campuran mie, tahu dan sayur. Cara pembuatan bakso ikan diilustrasikan pada Gambar 3.

Untuk menunjang proses produksi nugget dan bakso ikan, diberikan alat food processor, sehingga Kelompok Wanita Tani Senden dapat dengan mudah menggiling ikan untuk bahan baku nugget dan bakso.

\section{Memfasilitasi Pengemasan Produk Ola- han Ikan Air Tawar}

Proses kemasan melibatkan kegiatan mendesain dan memproduksi, fungsi utama dari kemasan sendiri yaitu untuk melindungi produk agar produk tetap terjaga kualitasnya (Kotler dan Amstrong, 2012). Kemasan yang baik dapat membangun ekuitas merek dan mendorong penjualan(Kotler dan Keller, 2012).

Menurut Wijayanti (2012), kemasan mempunyai tujuan dan fungsi dalam pembuatan produk, yaitu: (1) memperindah produk dengan kemasan yang sesuai kategori produk; (2) memberikan keamanan produk agar tidak rusak; (3) memberikan keamanan produk pada saat pendistribusian produk; (4) memberikan informasi pada konsumen tentang produk itu sendiri dalam bentuk pelabelan;(5) merupakan hasil desain produk yang menunjukan produk tersebut.

Begitu pentingnya fungsi kemasan dalam suatu produk, mendasari kegiatan pengabdian ini juga memfasilitasi penge- 
masan produk olahan ikan air tawar.Untuk itu dirancang desain pengemasan produk yang menarik dan bersifat informatif. Kemasan untuk ketiga produk olahan ikan tersebut diilustrasikan pada Gambar (4). Jenis kemasan yang digunakan adalah kemasan plastik.

Untuk menunjang fasilitas pengemasan, kegiatan pengabdian ini juga memberi alat untuk mengemas, yaitu sealer. Selain itu, bakso ikan dikemas secara vakum untuk memperpanjang masa simpan bakso. Pengemasan vakum adalah pengemasan yang memindahkan semua udara dalam kemasan tanpa menggantinya dengan gas lain (Syarief et al.1989). Oleh karena itu, disediakan juga fasilitas alat pengemasan vakum.

\section{Pelatihan Manajemen Penyimpanan (Storage Management)}

Teknik dan strategi penyimpanan produk yang siap dipasarkan juga menjadi kunci keberhasilan industri pangan olahan karena berpengaruh dalam menjaga kualitas produk dalam waktu lama sampai produk beralih kepada konsumen. Ketidaktepatan teknik penyimpanan produk akan mengakibatkan kerusakan produk sehingga menurunkan kualitas.
Penyimpanan kerupuk dilakukan jika produk tidak ingin didistribusikan langsung, maka kerupuk lebih baik disimpan dulu. Untuk menjaga kestabilan harga produk di pasar, kerupuk disimpan di tempat yang aman, terhindar dari jangkauan binatang, suhu yang lembab, lantainya bersih, dan tempatnya yang cukup luas. Kerupuk disusun secara rapi dengan cara ditumpuk, tetapi sebelum ditumpuk terlebih dahulu dilapisi kardus dengan papan kayu untuk menghindari kerusakan. Jumlah tumpukan kardus maksimal delapan tumpukan dan produk harus dikelompokan sesuai dengan tanggal penyimpanan. Produk yang terlebih dahulu disimpan, pendistribusiannya harus didahulukan, untuk mencegah kerusakan.

Sedangkan untuk penyimpanan produk nugget dan bakso ikan, agar tahan lama disimpan dalam freezer. Penyimpanan produk pangan olahan dengan pembekuan merupakan proses mengawetkan produk makanan dengan cara mengubah hampir seluruh kandungan air dalam produk menjadi es. Keadaan beku menyebabkan aktivitas mikrobiologi dan enzim terhambat sehingga daya simpan produk menjadi panjang. Pengadaan freezer menjadi kebutuhan penting untuk industry olahan ikan air tawar ini.

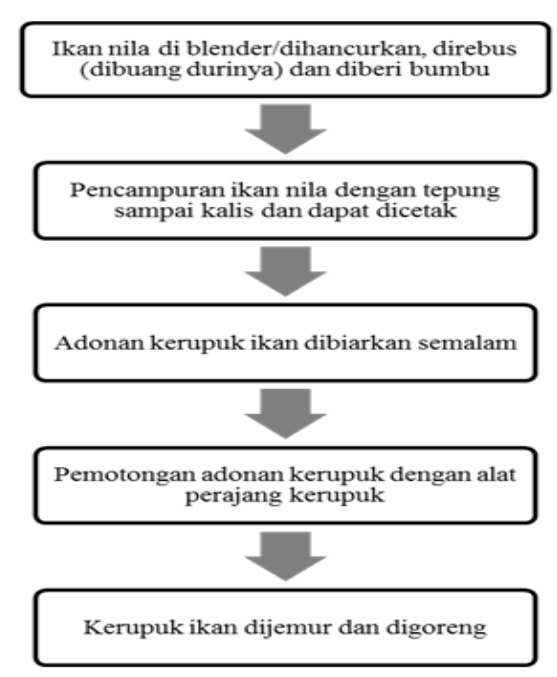

Gambar 1. Cara Pengolahan Ikan Nila Menjadi Kerupuk Ikan pada pengolahan ikan menjadi kerupuk ikan, diberikan bantuan alat perajang kerupuk. 


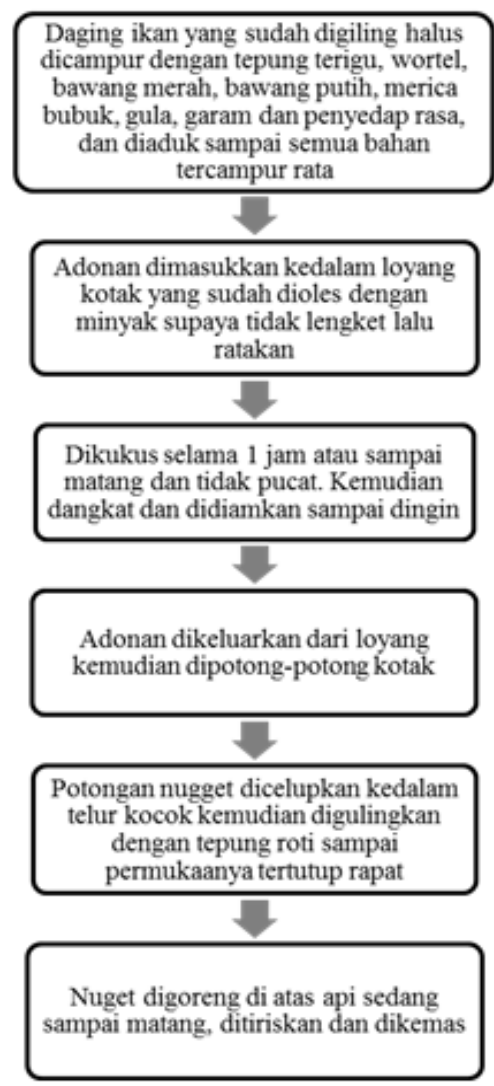

Gambar 2. Cara Pengolahan Ikan Air Tawar Menjadi Nugget Ikan

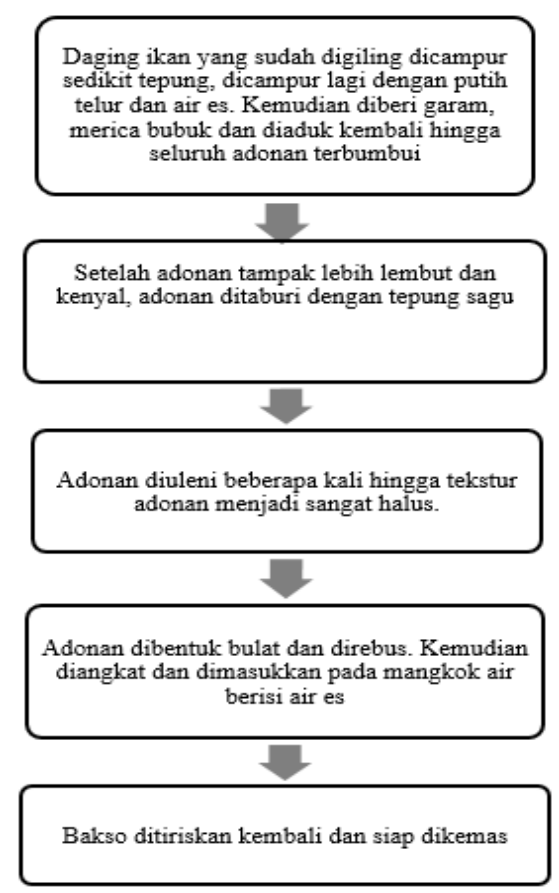

Gambar 3. Cara Pengolahan Ikan Air Tawar Menjadi Bakso Ikan 


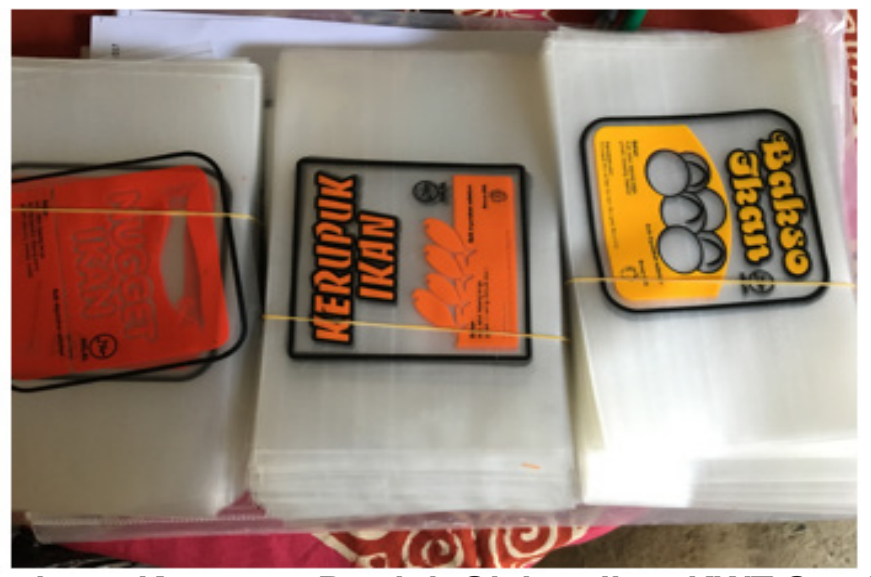

Gambar 4.Kemasan Produk Olahan Ikan KWT Senden

\section{Kesimpulan}

Kegiatan action research ini dilakukan dengan memberikan pelatihan : (a) pengolahan ikan nila menjadi kerupuk ikan, nugget ikan dan bakso ikan, (b) memfasilitasi pengemasan produk olahan ikan air tawar sekaligus memberikan pelatihan manajemen penyimpanan (Storage Management)

Kegiatan ini telah memberikan bantuan peralatan kepada kelompok sasaran berupa : (a) Mesin perajang kerupuk, (b Food processor, (c) Freezer, (d) Sealer, (e) Mesin pengemas vacum, (f) Loyang Nugget

\section{Daftar Pustaka}

Antriyandarti, E dan Fukui, Seiichi.Impact of Rice Trade Liberalization on Farm Households In Central Java. SEPA. September 2010 Vol 7 (1): 23-29.

Antriyandarti, E. Competitiveness and Cost Efficiency of Rice Farming in Indonesia," Journal of Rural Problems, 2015. Vol. 51 (2): 74-85.

Antriyandarti, E. 2016. An Economic Study of the Indonesian Rice Sector: Toward Harmonization of Structural Adjustment and Food Security.Dissertation. Graduate School of Agriculture, Kyoto University. Japan.
Babatunde, R. O., and M. Qaim. 2009. The Role of Off-farm Income Diversification in Rural Nigeria: Driving Forces and Household Access." CSAE conference on economic development in Africa, St Catherine's College, Oxford, March 22-24, 2009, http://www.csae.ox.ac.uk/ conferences/2009-EDiA/papers/051Babatunde.pdf, 2016/02/18.

Cavestro, L. 2003. P.R.A. - Participatory Rural Appraisal Concepts Methodologies and Techniques.Padova University. Padova PD. Italia

De Janvry, A., Sadoulet, E., and Zhu, N. 2005.The Role of Non-Farm Income in Reducing Rural Poverty and Inequality in China, Department of Agricultural \& Resource Economics, UC Berkeley, Working Paper No. 1001, http://are. berkeley.edu/ esadoulet/papers/RNFNong.pdf, 2016/02/15.

Godoy, D. C., and Dewbre, J. 2010. Economic Importance of Agriculture for Sustainable Development and Poverty Reduction: Findings from a Case Study of Indonesia.Global Forum on Agriculture 29-30, November 2010, Policies for Agricultural Development, Poverty Reduction and Food Security OECD Headquarters, Paris.http://www. oecd.org/agriculture/agriculturalpolicies/46341215.pdf, 2016/02/12. 
Kotler, P. dan Armstrong, G. 2012.Principles of Marketing. New Jersey: Prentice Hall.

Kotler, P. dan Keller, K.L. 2012.Marketing Management.14th Edition. United States of America : Pearson.

Syarief, R., Santana, S., Ismayana, B. 1989. Teknologi Pengemasan Pangan. Bogor: Laboratorium Rekayasa Pangan. Pusat Antar Universitas Pangan dan Gizi, Institut Pertanian Bogor.

Uphoff, N.,1988. "Menyesuaikan Proyek pada Manusia" dalam Mengutamakan Manusia di dalam Pembangunan, ed, Michael M. Cernea. Publikasi Bank Dunia.Jakarta: UI Press.

Wijayanti, T. 2012. Management Marketing Plan. Jakarta: Elex media. Komputindo.

World Bank. 2004. Strategic Framework for Assistance to Africa. The World Bank. Washingto 